\title{
Other Organism Groupings
}

National Cancer Institute

\section{Source}

National Cancer Institute. Other Organism Groupings. NCI Thesaurus. Code C14376.

A non-taxonomic grouping of organisms based on a shared characteristic. 